\title{
Mudanças climáticas e a cana-de-açúcar no Brasil: Fisiologia, conjuntura e cenário futuro
}

\author{
Fabio Marin ${ }^{1} \&$ Daniel S. P. Nassif ${ }^{2}$
}

\begin{abstract}
RESUMO
Com base na revisão de literatura, o manuscrito analisa qualitativamente um futuro cenário para a canade-açúcar no Brasil, com base na tendência de expansão da cultura observada ao longo da última década, a conjuntura atual do setor e as projeções de mudanças climáticas globais regionalizadas para este século. O principal foco foi associar os resultados científicos sobre a fisiologia da cana-de-açúcar e suas respostas à elevação na concentração de dióxido de carbono atmosférico e eficiência de uso da água com as perspectivas socioeconômicas do setor canavieiro do Brasil. Prováveis efeitos sobre plantas daninhas, pragas e doenças da cana-de-açúcar, também foram abordados. A base do conhecimento disponível na literatura indica que a cana-de-açúcar apresentaria uma resposta positiva em relação aos cenários de mudanças climáticas mais prováveis para o Brasil, tanto pela resposta direta da fotossíntese à elevação na concentração do dióxido de carbono quanto ao aumento da eficiência de uso da água. Contudo, é provável que o manejo na cultura necessite de adaptações uma vez que plantas daninhas e doenças poderiam ser favorecidas pelas condições futuras.
\end{abstract}

Palavras-chave: dióxido de carbono, fisiologia, plantas C4, eficiência de uso da água

\section{Climate change and the sugarcane in Brazilian: Physiology, conjuncture and future scenario}

\begin{abstract}
Based on literature, this paper examines qualitativelly a future scenario for the sugarcane in Brazil. It was done considering the expanding trend of the crop observed over the last decade, the current sector conjuncture, and the down scaled climate change projections for this century. The focus was to associate the scientific findings on the physiology of sugarcane and their responses to the rise in atmospheric $\mathrm{CO}_{2}$ concentration and the water use efficiency with socio-economic prospects for the sugarcane industry in Brazil. Probable effects on weeds, diseases and pest of sugarcane crop were also analysed. Available literature indicates that sugarcane crop would likely show a positive response to probably scenarios of climate change in Brazil due both to direct response of photosynthesis in view of increase of carbon dioxide and the higher water use efficiency. However, it is likely that the crop management may require adaptation to the future climate, since weeds and diseases could be favored under the future climate.
\end{abstract}

Key words: carbon dioxide, physiology, C4 plants, water use efficiency 


\section{INTRODUÇÃO}

A variabilidade e a mudança climática causadas por processos naturais e antropogênicos devem afetar o processo produtivo e o modo de vida da humanidade, no século 21. As estimativas recentes de aumento de temperatura do Painel intergovernamental de Mudanças Climáticas (International Panelon Climate Change - IPCC) no Quarto Relatório de Avaliação (AR4) estão entre 1,8 e $3,6^{\circ} \mathrm{C}$ e a concentração de $\mathrm{CO}_{2}$ estimada em 720 ppm no período entre 2090 a 2099. Países dependentes dos recursos naturais e exportadores de commodities, como ainda é o caso do Brasil, podem sofrer os impactos de eventos extremos, de modo mais pronunciado do ponto de vista econômico e social.

Apesar de recentes, as pesquisas enfocando este aspecto já trouxeram resultados que permitem inferir sobre os efeitos das projeções climáticas na cultura da cana-de-açúcar considerandose as tendências futuras para o setor. Ao se considerar a tendência de expansão da cultura observada ao longo da última década e a conjuntura atual do setor, pode-se traçar um cenário qualitativo de médio prazo levando em conta as mudanças climáticas globais e a respostas fisiológicas da cultura aos elementos climáticos mais prováveis de serem alterados neste período.

Com base em revisão de literatura buscou-se redigir este manuscrito de modo multidisciplinar, os resultados científicos sobre a fisiologia da cana-de-açúcar e suas respostas a um provável clima futuro, em associação com as perspectivas socioeconômicas do setor canavieiro do Brasil.

\section{HistóRICO E A CONJUNTURA ATUAL}

Duas espécies de cana-de-açúcar foram descritas em 1753, por Lineu: Saccharum officinarum e Sacharum spicatum que, atualmente, são classificadas como $S$. officinarum, $S$. spontaneum, S. sinensis, S. barberi e S. robustum, pertencentes à família Poacea. Nas Índias, a cana-de-açúcar já era utilizada desde 1500 a.C (Aranha \& Yan, 1987). A Nova Guiné é considerada o centro de origem da cultura haja vista foram encontrados registros com mais de 8000 anos. Há também indícios de que, neste período, a cana-de-açúcar era utilizada também na China (James, 2004). Desde então, a cana-de-açúcar é uma das culturas de metabolismo C4 mais importante do mundo para a produção de alimentos, fornecendo cerca de $75 \%$ da colheita mundial de açúcar para o consumo humano (Souza et al., 2008)

No Brasil, a cana-de-açúcar chegou logo após o descobrimento do País, para quebrar o monopólio francês no suprimento mundial de açúcar, oriundo das colônias caribenhas (Canabrava, 2005). A cultura ganhou importância econômica mais expressiva a partir da segunda metade do século XVI, quando os engenhos do nordeste brasileiro passaram a operar em Pernambuco, Bahia, Alagoas, Sergipe e Paraíba. No século XVII a produção de cana-de-açúcar expandiu-se para o Pará e Amazonas (onde os engenhos foram orientados para a produção de cachaça) chegando, em seguida, ao Ceará, Piauí e Rio Grande do Norte. Neste período a cultura atendia perfeitamente à estratégia de Portugal, associando a ocupação intensa da colônia e a produção de um item altamente lucrativo para a metrópole na Europa (Canabrava, 2005).
No século XIX a expansão dos polos produtores de açúcar pelo mundo reduziu a importância do Brasil no mercado mundial comprometendo, assim, a viabilidade econômica da atividade interna. Neste período, São Paulo e Rio de Janeiro se firmaram como polos fornecedores para as regiões Sul e Sudeste. Em 1933 foi criado o Instituto do Açúcar e do Álcool (IAA) com a finalidade de regular a produção interna e desenvolver pesquisas sobre a cultura. Em 1973 o Brasil iniciou, com a primeira crise do petróleo, o Programa Nacional do Álcool - ProÁlcool, com o objetivo de inserir o etanol na matriz energética brasileira. Em 1979 iniciou-se a produção de veículos movidos a etanol no Brasil. O baixo preço do produto atraiu a classe média e, em 1985, 96\% dos veículos fabricados no País eram movidos a etanol. Porém na segunda metade da década de 80 houve escassez de crédito para os produtores de cana-de-açúcar, diminuição nos preços pagos ao produtor de álcool e preços atrativos do açúcar no mercado internacional, culminando na escassez de etanol no mercado interno e no comprometimento da credibilidade do setor perante o consumidor final (Nitsch, 1991).

Desde o início da década passada, o Brasil se tem destacado pelo grande potencial para a agricultura de energia a partir de biocombustíveis, com 596 usinas operando em 2010 (Figura 1).

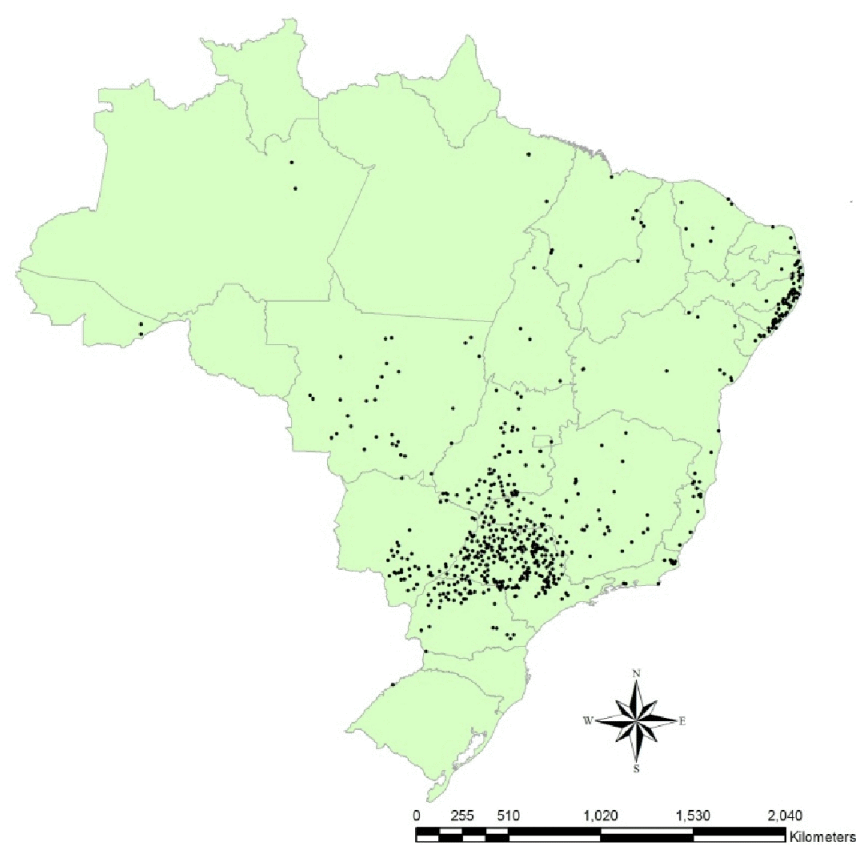

Fonte: Embrapa CNPTIA

Figura 1. Distribuição espacial das usinas sucroalcooleiras e de biodiesel no Brasil, no ano de 2010

Segundo a Companhia Nacional de Abastecimento (CONAB, 2011) a área de cana-de-açúcar no Brasil cresceu 19\% em Goiás, 32\% em Mato Grosso do Sul, $42 \%$ no Tocantins e $26 \%$ no Paraná, entre 2006 e 2009. Em São Paulo, que responde atualmente por $52,7 \%$ da área plantada e $58,2 \%$ da produção nacional de cana-de-açúcar, houve avanço de $11 \%$ no mesmo período (Figura 2).

No caso do açúcar, o Brasil ocupa mais de $40 \%$ do mercado internacional. A demanda externa tem impulsionado sua expansão devido ao crescimento da população mundial 


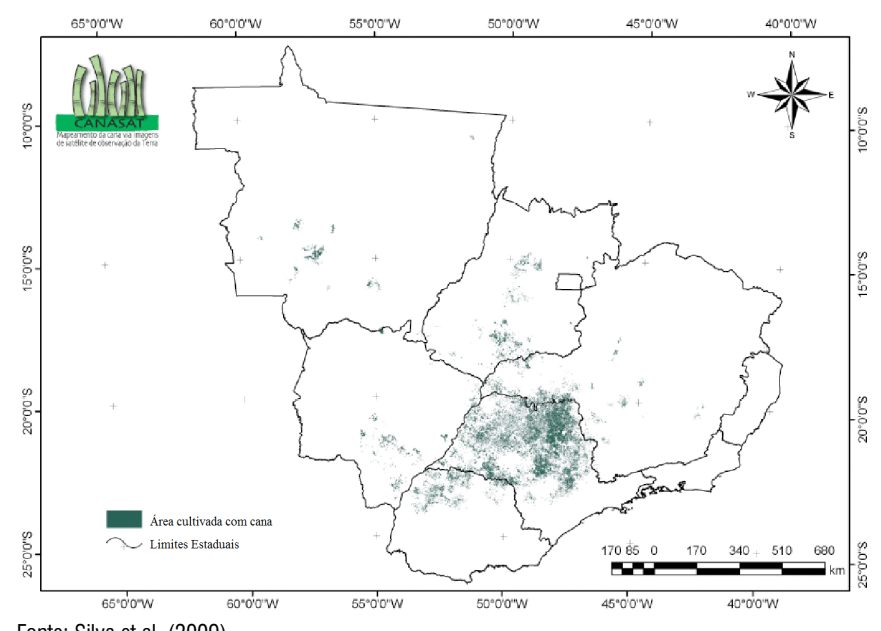

Fonte: Silva et al. (2009)

Figura 2. Distribuição espacial das áreas cultivadas com cana-de-açúcar na região Centro-Sul - safra 2008/2009

e ao aumento do consumo em países em desenvolvimento, particularmente na Ásia, face ao crescimento da renda per capita e ao processo de êxodo rural nesses países. Mais recentemente, a quebra de safra em países produtores representou incentivo adicional para o produto no mercado externo, afetando o mercado interno de etanol.

Atualmente, o Brasil é o segundo maior produtor mundial de etanol, pouco abaixo dos Estados Unidos, que utilizam o milho para sua produção. As condições pedoclimáticas e a larga experiência acumulada na produção de álcool combustível colocam o Brasil em posição privilegiada em relação aos demais países produtores. Durante a safra 2011/2012, 571milhões de toneladas de cana-de-açúcar colhidas produziram aproximadamente 36,9 milhões de toneladas de açúcar e cerca de 22,8 bilhões de litros de etanol (CONAB, 2011). Além de seu uso comercial para açúcar, etanol e eletricidade nas usinas, a cultura é amplamente utilizada por pequenos agricultores, em todo o País, como alimento para animais ou como matéria-prima para a cachaça artesanal e açúcar mascavo.

Para os países que são altamente dependentes dos recursos naturais, como o Brasil, os impactos de eventos extremos podem ter uma importância econômica e social que superam de longe suas probabilidades de ocorrência aparente (Thornton et al., 2009). Esses impactos sobre a agricultura têm importância especial para o Brasil, uma vez que quase $30 \%$ do produto interno bruto brasileiro estão relacionados ao agronegócio (Barros, 2009). Apesar desses números expressivos, o setor passa, nos últimos 3 anos, por uma importante crise, decorrente de três causas principais (Bressan Filho, 2009): 1) a crescente necessidade de capital financeiro para a formação de estoques de etanol e garantia de oferta do produto na entressafra; 2) a baixa taxa de remuneração da atividade alcooleira nas safras 2007/2008 e 2008/2009 e 3) ausência de mecanismos comerciais para interferir na formação das margens de comercialização e na competitividade do etanol, frente à gasolina. Considerando que os preços atuais do etanol e do açúcar são remuneradores, é razoável supor que a tendência de expansão da área de cana seja mantida, ainda que em taxas inferiores àquelas observadas na última década.

\section{A FISIOLOGIA DA CANA-DE-AÇÚCAR E OS CENÁRIOS CLIMÁTICOS FUTUROS}

O IPCC apresentou, no Quarto Relatório de Avaliação (AR4) as estimativas recentes de aumento de temperatura, que estão na faixa de $1,8-3,6{ }^{\circ} \mathrm{C}$ e de aumento na $\left[\mathrm{CO}_{2}\right]$, podendo chegar a $720 \mathrm{ppm}$ em 2090-2099, dependendo do cenário de emissão de gases de efeito estufa considerada nos modelos climáticos (Trenberth et al., 2007). As projeções de variabilidade e mudança climática indicam para alterações na umidade do solo e da frequência de eventos extremos de alta temperatura, inundações e secas em muitas localidades (Alexandrov \& Hoogenboom, 2000). Bombardi \& Carvalho (2008) sugeriram que na região Centro-Oeste do Brasil, onde estão as maiores áreas de expansão da cana-de-açúcar, deverá ocorrer um aumento na ocorrência de eventos extremos, tanto de anos mais chuvosos quanto de anos mais secos. Este cenário de maior fragilidade climática é especialmente importante para culturas com ciclos mais longos, mais expostas aos riscos climáticos, como é o caso da cana-de-açúcar.

A cana-de-açúcar é uma planta de metabolismo $\mathrm{C} 4$, que tem um mecanismo de concentração de $\mathrm{CO}_{2}$ nas células do mesófilo mobilizando as moléculas de $\mathrm{CO}_{2}$ e transportando-as na forma de uma molécula de quatro carbonos para descarboxilação nas células da bainha vascular (Allen et al., 1985). O mecanismo de concentração de $\mathrm{CO}_{2}$ nas células do mesófilo permite às plantas $\mathrm{C} 4$, contudo, fechar parcialmente os estômatos reduzindo a condutância estomática e a transpiração quando submetidas a elevadas concentrações de $\mathrm{CO}_{2}$.

As respostas de espécies $\mathrm{C} 4$ ao aumento na $\left[\mathrm{CO}_{2}\right]$ são variáveis entre as espécies mas em seu levantamento, Drake et al. (1997) encontraram, em 41 artigos abrangendo 28 espécies, diminuição média da condutância estomática de cerca de $20 \%$. Assim e em virtude dessas características anatômicas e fisiológicas, espera-se que as plantas $\mathrm{C} 4$ respondam de modo mais pronunciado à elevação na $\left[\mathrm{CO}_{2}\right]$ fechando os estômatos em maior medida do que as espécies C3 (Tolbert \& Zelich, 1983). Alguns autores assumem que as folhas das plantas $C 4$ estejam saturadas de $\mathrm{CO}_{2}$ do ambiente e que, portanto, elas seriam menos afetadas pelo aumento da $\left[\mathrm{CO}_{2}\right]$ que as plantas C3. Ottman et al. (2001) e Leakey et al. (2006) mostraram que o sorgo e o milho bem adubados e irrigados, não responderam à elevação na $\left[\mathrm{CO}_{2}\right]$.

Na revisão de DaMatta et al. (2010) envolvendo espécies C3 e C4, a condutância estomática foi consistentemente reduzida conforme a $\left[\mathrm{CO}_{2}\right]$ foi elevada (Ainsworth \& Long, 2005; Leakey et al., 2009; Ziska \& Bunce, 2006). Quando a elevação da $\left[\mathrm{CO}_{2}\right]$ ocorre junto com a elevação da temperatura, com ou sem estresse hídrico, as plantas de metabolismo $\mathrm{C} 4$ apresentam elevação da produtividade, o que foi demonstrado por Morgan et al. (2011) em espécies C4, neste estudo, o aumento da $\left[\mathrm{CO}_{2}\right]$ elevou a eficiência do uso da água e, por outro lado, causa um aumento na produção de biomassa e, consequentemente, um aumento na superfície de transpiração. Os mesmos autores demonstraram que quando ocorre um aumento da temperatura em conjunto com elevação da $\left[\mathrm{CO}_{2}\right]$, a produtividade das plantas $\mathrm{C} 4$ elevou-se. Conforme a Tabela 1, o aumento significativo na fotossíntese e a produção de biomassa, mesmo sob condições irrigadas e sem restrição nutricional, foram relatados por alguns 
Tabela 1. Resposta da cultura da cana-de-açúcar à elevação da $\left[\mathrm{CO}_{2}\right]$ para 720 ppm para a fotossíntese, biomassa (Bio), condutividade estomática (gs), transpiração (E) e eficiência do uso da água (EUA)

\begin{tabular}{lccccc}
\hline \multicolumn{1}{c}{ Referências } & Fotos & Bio & gS & E & EUA \\
Vu et al. (2006) & $+8-17 \%$ & $+37 \%$ & $-51 \%$ & $-39 \%$ & $+26-52 \%$ \\
Souza et al. (2008) & $+30 \%$ & $+40 \%$ & $-37 \%$ & $-32 \%$ & $+62 \%$ \\
Vu \& Allen Jr. (2009) & $+26 \%$ & $+12-71 \%$ & $-34 \%$ & $-25 \%$ & $+35 \%$ \\
\hline
\end{tabular}

autores em cana-de-açúcar (Vu et al., 2006; Souza et al., 2008; Vu \& Allen Jr., 2009). Eles reportaram um aumento de 30\% na fotossíntese e $40 \%$ na biomassa produzida para plantas que cresceram em $\left[\mathrm{CO}_{2}\right]=720 \mathrm{ppm}$, em câmaras de topo aberto. Além de também uma redução na condutância estomática e transpiração de mais de $30 \%$.

No experimento de $\mathrm{Vu}$ et al. (2006) foram incluídos tratamentos com temperatura do ar elevada combinada com a elevação da $\left[\mathrm{CO}_{2}\right]$ observando aumentos ainda maiores de massa seca do colmo $(+84 \%)$ e de caldo $(+124 \%)$ em comparação com o tratamento em que a concentração de $\left[\mathrm{CO}_{2}\right]$ foi elevada mantendo-se a temperatura constante. Apesar das diferenças que podem ser esperadas em condições de campo, os resultados de Souza et al. (2008) e Vu \& Allen Jr (2009) indicam que a fertilização de $\mathrm{CO}_{2}$ tem efeito pronunciado sobre a produção de cana.

$\mathrm{O}$ aumento na $\left[\mathrm{CO}_{2}\right]$ atmosférico eleva o gradiente que comanda a difusão de $\mathrm{CO}_{2}$ da atmosfera para o cloroplasto; esperaram-se, então, maiores taxas de fotossíntese para uma mesma condutância estomática. Em paralelo se tem, mantendose o mesmo déficit de pressão de vapor estômato-atmosfera, redução na taxa de transpiração. Assim, menores valores de condutância estomática ajudariam a reduzir o fluxo de seiva e aumentariam o potencial de água no xilema, levando a uma melhoria no status hídrico da planta (Owensby et al., 1997). Com isto, a elevação na $\left[\mathrm{CO}_{2}\right]$ melhoraria, em última análise, a eficiência do uso da água reduzindo os períodos de esgotamento da umidade do solo e amenizando o período de estresse durante a estação seca (Leakey et al., 2009). Destaca-se, também, que o fechamento dos estômatos geralmente observado quando a $\left[\mathrm{CO}_{2}\right]$ é elevada, pode estar associado à menor perda de calor latente e consequente elevação na temperatura foliar (Kimball \& Bernacchi, 2006).

Allen et al. (1985) sintetizaram uma relação matemática relacionando a $\left[\mathrm{CO}_{2}\right]$ atmosférica com o aumento da resistência estomática de milho doce, baseados no trabalho de Rogers et al. (1983); esses dados resultaram na seguinte relação empírica:

$$
\mathrm{r}_{\mathrm{s}}=\left(3,28 \times 10^{-2}-5,49 \times 10^{-5}\left[\mathrm{CO}_{2}\right]+2,96 \times 10^{-8}\left[\mathrm{CO}_{2}\right]^{2}\right)^{-1}
$$

em que:

rs - resistência foliar à difusão de vapor d'água, $\mathrm{m} \mathrm{s}^{-1}$

$\left[\mathrm{CO}_{2}\right]$ - concentração de $\mathrm{CO}_{2}$ mmol mol${ }^{-1}$

A Eq. 1 fornece estimativas de resistência estomática de $62 \mathrm{e}$ $135 \mathrm{~m} \mathrm{~s}^{-1}$ para $\left[\mathrm{CO}_{2}\right]$ de 380 e $880 \mathrm{mmol} \mathrm{mol}^{-1}$, respectivamente. Apesar de terem sido derivados do milho doce, esses valores são similares aos observados em cana-de-açúcar cultivada em ambientes enriquecidos com $\mathrm{CO}_{2}$ por Venkataramana et al.
(1986), Grantz \& Meinzer (1990), Souza et al. (2008) e Vu \& Allen Jr. (2009) e dão boa indicação sobre uma abordagem viável para a modelagem desse processo, em cana-de-açúcar.

A elevação da $\left[\mathrm{CO}_{2}\right]$ em plantas $\mathrm{C} 4$ tem, como consequência, o aumento na taxa de assimilação via aumento da pressão parcial de $\mathrm{CO}_{2}$ intercelular, melhoria nas relações hídricas, devido à redução da condutividade estomática e consequente redução dos efeitos negativos do estresse hídrico no crescimento das folhas e o aumento da temperatura foliar, estimulando a divisão e a expansão celular elevando, assim, o acúmulo de biomassa (Ghannoum et al., 2000).

\section{EFEITO DAS MUDANÇAS CLIMÁTICAS EM PLANTAS DANINHAS, PRAGAS E DOENÇAS}

As plantas daninhas causam perdas substanciais de produtividade, particularmente no desenvolvimento das culturas, quando em competição. As mesmas devem ser afetadas diretamente pelo aumento da [CO2] na atmosfera, sendo beneficiadas como as culturas econômicas, sendo o efeito das mudanças climáticas serão dependente da espécie (Patterson et al., 1999). Ziska \& Bunce (1997) confirmaram que o aumento na $\left[\mathrm{CO}_{2}\right]$ resulta em resposta direta das plantas daninhas que receberam o estímulo, com elevação na taxa fotossintética semelhante às respostas das plantas $\mathrm{C} 3$, podendo chegar a duas vezes o ganho fotossintético em relação às plantas cultivadas.

Em sorgo anão (Sorghum bicolor cv. 'Martim') cultivado com a presença da planta daninha caruru (Amaranthus retroflexus L.), Ziska (2003) observou que a competição em ambiente com $\left[\mathrm{CO}_{2}\right]$ elevado resultou em perda de rendimento da cultura de até $23 \%$ em relação à testemunha. O estabelecimento das plantas daninhas também pode ser favorecido devido ao aumento da umidade do solo em áreas não irrigadas, causado pela melhor eficiência do uso da água pelas plantas cultivadas em ambientes com alta $\left[\mathrm{CO}_{2}\right]$ (Fuhrer, 2003). Isso provavelmente, levaria à necessidade de adaptação do manejo das plantas daninhas na cultura da cana-de-açúcar.

As doenças de plantas dependem do clima e do tempo para sua ocorrência. Contudo, os efeitos das mudanças climáticas em pragas e doenças raramente são levados em conta nas avaliações de possíveis impactos das mudanças climáticas em agroecossistemas (Fuhrer, 2003). Apesar disto, é fácil supor que a distribuição e o grau de infestação serão alterados com as mudancas no clima, seja pelos efeitos diretos no ciclo de vida dos insetos, pelos efeitos climáticos nos hospedeiros e, sobretudo, pelos efeitos das mudanças na temperatura, distribuição de chuvas e padrões de vento (Patterson et al., 1999).

Em uma atmosfera com maiores concentrações de $\mathrm{CO}_{2}$, um aumento da população de pragas pode ser possível tendo, como implicação, uma modificação no manejo das pragas (Fuhrer, 2003). Entretanto, Thomson et al. (2010) advertem que os efeitos das mudanças climáticas sobre o controle de pragas serão dados por um mecanismo complexo, em especial quando as culturas em expansão para novas áreas - como no caso da canade-açúcar - os vetores de doenças escapam temporariamente de inimigos naturais nessas novas áreas. 
Chakraborty et al. (1998) alertaram para os prováveis impactos das mudanças climáticas na Austrália (elevação na $\left[\mathrm{CO}_{2}\right]$ e temperaturas máximas e mínimas, além de modificações nos eventos extremos) na distribuição geográfica das doenças devido às mudanças na fisiologia da interação do sistema patógeno-hospedeiro, em que a resistência do hospedeiro pode ser superada em razão da evolução acelerada do patógeno. Segundo Fuhrer (2003) a ocorrência de invernos mais quentes favoreceria doenças fúngicas enquanto, por outro lado, verões mais secos teriam efeito depressor na incidência de doencas. Levando em conta os cenários propostos por Trenberth et al. (2007) e Alves \& Marengo (2010) pode-se inferir que as principais doenças que ocorrem na cana-de-açúcar do Brasil, seriam favorecidas por tais cenários futuros.

As mudanças climáticas podem alterar os estágios e as taxas de desenvolvimento dos patógenos, modificar a resistência do hospedeiro, tendo como consequências mais prováveis as mudanças da distribuição geográfica do patógeno e a alteração das perdas causadas, em parte, pelas mudanças na eficácia das estratégias de controle (Coakley et al., 1999).

ANALISANDO A EXPANSÃO DA CANA-DE-AÇÚCAR À LUZ DA CIÊNCIA CLIMÁTICA E FISIOLÓGICA

Os resultados do Zoneamento Agroecológico da Canade-Açúcar (Manzatto et al., 2009) (Figura 3) mostraram a disponibilidade de $6610^{6}$ ha de áreas aptas à expansão do cultivo com cana-de-açúcar, sendo que $19,310^{6}$ ha foram considerados com alto potencial produtivo, 41,6 $10^{6}$ ha como médio e $510^{6}$ ha como de baixo potencial para o cultivo. A região Centro Oeste apresenta o maior percentual de terras aptas à expansão do cultivo com cana-de-açúcar com $45 \%$ do total estimado, seguida das regiões Sudeste 34,5\%, Sul 11,2\%, Nordeste 7,6\% e pelo Estado do Tocantins na Região Norte, com 1,7\%.

Apesar da boa regularidade e dos elevados volumes de chuva na maior parte do Brasil durante o verão, o longo período de estiagem é limitador do acúmulo de biomassa por causa da baixa umidade do solo durante praticamente todo o outono

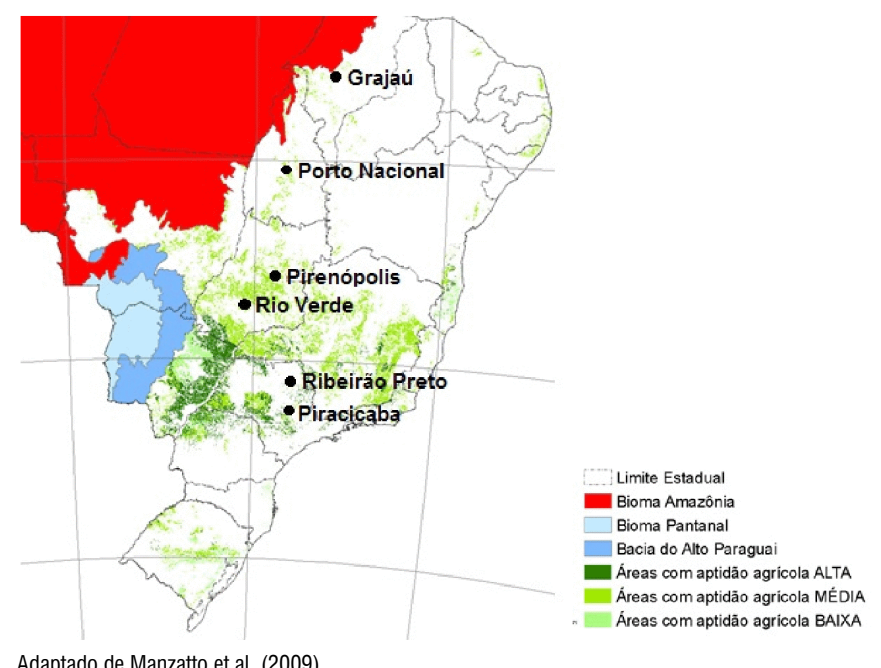

Figura 3. Áreas de expansão do Zoneamento Agroecológico da cana-de-açúcar e o inverno. Tal limitação hídrica acarreta o fechamento dos estômatos e, consequentemente, queda nas taxas de fotossíntese, sobretudo entre os meses de abril e novembro, compreendendo a fase final de crescimento vegetativo, a fase de maturação e o início do período de perfilhamento da cultura.

Considerando a reação da cana-de-açúcar à fertilização pelo $\mathrm{CO}_{2}$ atmosférico elevado, este quadro de estresse por deficiência hídrica poderia ser reduzido, caso as projeções climáticas fossem confirmadas. Disto decorre que as áreas que hoje apresentam certa limitação à produção canavieira devido ao estresse hídrico, devem ser mais beneficiadas que aquelas que ocupam, hoje, regiões adequadas à produção de cana-deaçúcar quanto ao suprimento hídrico.

Tais informações são interessantes no presente contexto uma vez que revelam a tendência de expansão da cana-de-açúcar para uma região em que o estresse hídrico relativamente maior é uma das principais limitações à obtenção de rendimentos elevados. Grande parte da área para o cultivo futuro da cana-de-açúcar ocorrerá em áreas de pastagens degradadas, principalmente na região Centro-Oeste, onde é necessária a utilização da irrigação da cana-de-açúcar, tanto de salvamento como complementar, durante a estação seca, sendo outro indicador do estresse hídrico enfrentado pela cultura no cerrado brasileiro (Manzatto et al., 2009). Já na região Nordeste do Brasil, devido às condições climáticas, principalmente nos tabuleiros costeiros, é comum a utilização da irrigação complementar na cultura, o que evitaria o prejuízo com a morte de soqueiras e necessidade de renovação precoce do canavial (Farias et al., 2008). Outro ponto relevante diz respeito à relação às perspectivas de mudanças climáticas. Assad et al. (2008) e Gouvêa et al. (2009) demonstraram que apesar de a cultura da cana-de-açúcar apresentar uma projeção de aumento de área apta ao cultivo, algumas regiões, como o centro-oeste do Brasil, poderiam tornar-se mais dependentes da irrigação complementar. Com base em Marin et al. (2012) é possível, contudo, inferir que o ganho em eficiência de uso decorrente da elevação da $\left[\mathrm{CO}_{2}\right]$ poderia reduzir essa tendência ou mesmo revertê-la, tornando as condições de estresse hídrico na região Centro-Oeste mais favoráveis à produção de canade-açúcar mantendo-se as mesmas condições de uso de água para a irrigação.

A Figura 4 ilustra os diferentes ambientes da cultura da cana-de-açúcar, em que Piracicaba e Ribeirão Preto representam a atual área canavieira e nas demais regiões, que são áreas de expansão, observa-se um balanço hídrico mais desfavorável para a cultura da cana-de-açúcar.

Considerando também os mapas de projeção apresentada para o Brasil, observam-se tendência de redução no volume de chuvas durante o verão e estabilidade no inverno para a região Centro-Sul, redução no volume de chuvas no inverno e estabilidade no verão para a região Nordeste (Trenberth et al., 2007; Alves \& Marengo, 2010). A princípio poder-se-ia esperar, com essas projeções associadas ao aumento de temperatura, um impacto negativo sobre a produção de cana-de-açúcar. No entanto, quando se inclui o efeito da elevação da $\left[\mathrm{CO}_{2}\right]$ na cultura o aumento da eficiência do uso da água pode compensar 
A. Piracicaba/SP

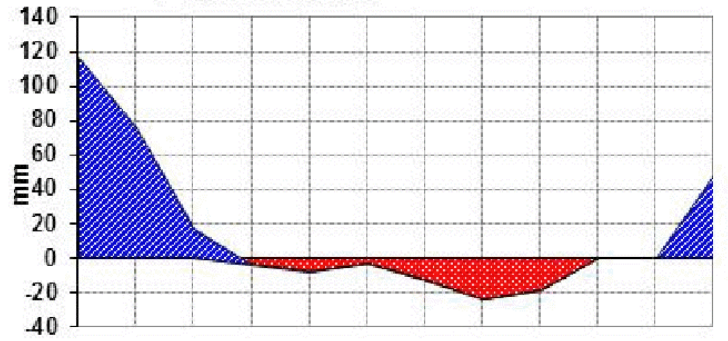

C. Rio Verde/Go

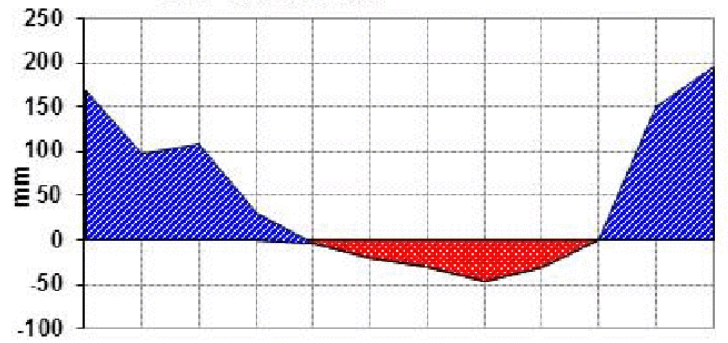

E. Porto Nacional/TO

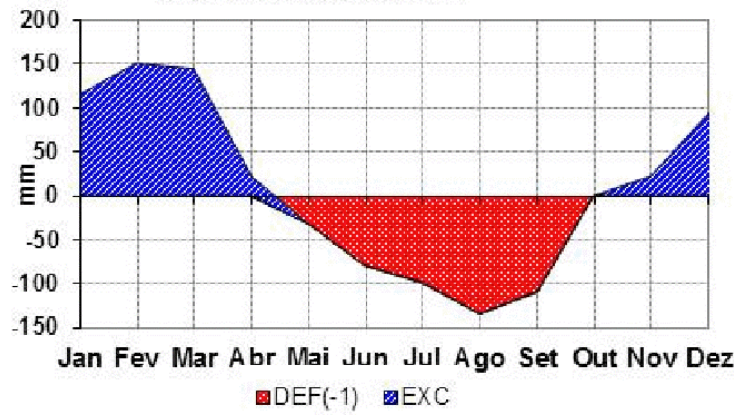

B.
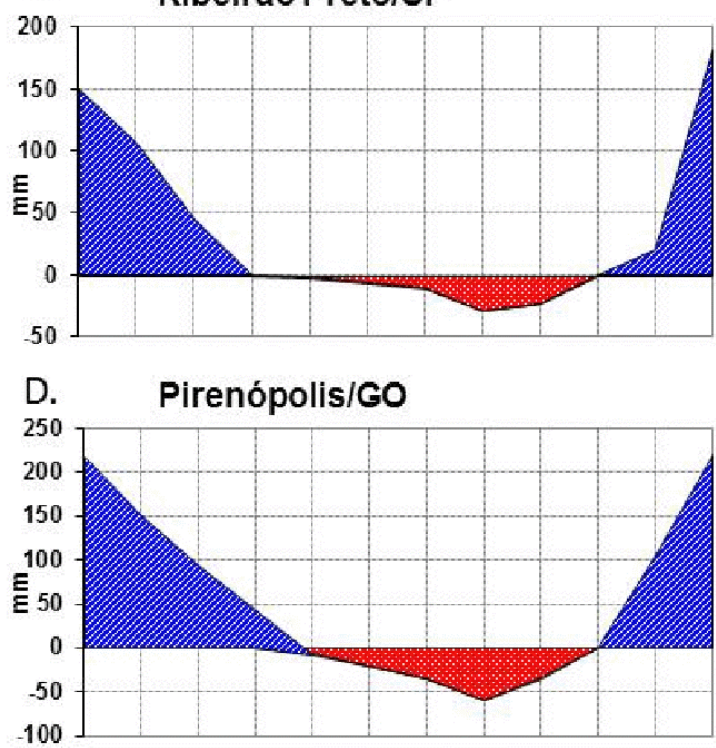

F.

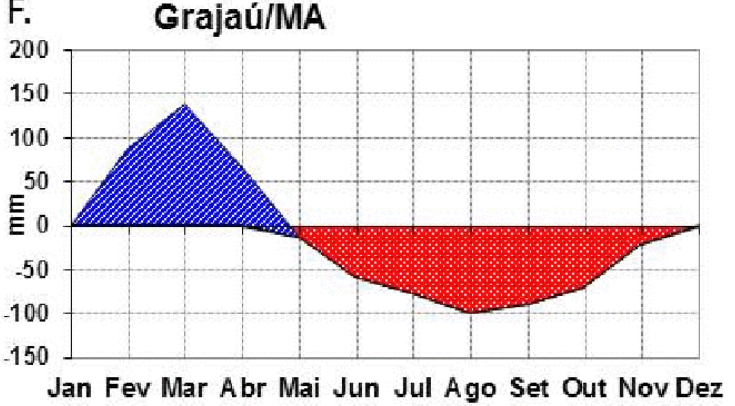

Fonte: Sentelhas et al. (1999)

Figura 4. Extrato do balanço hídrico climatológico para Piracicaba/SP (A), Ribeirão Preto/SP (B), Rio Verde/GO (C), Pirenópolis/GO (D), Porto Nacional/TO (E) e Grajaú (F), considerando-se CAD $=1 \mathrm{~mm} \mathrm{~cm}^{-1}$

a queda na disponibilidade de água mantendo a perspectiva de um cenário mais positivo para a cana-de-açúcar cultivada no Cerrado do Brasil (Marin et al., 2012).

Nesta linha é possível inferir que mesmo no Sudeste do Brasil, nas regiões com ambientes de produção $\mathrm{D}$ e E nas áreas tradicionais de cultivo da cultura, haja melhor aproveitamento da água disponível e redução do estresse fisiológico durante os períodos de estiagem, tornando tais áreas mais aptas ao cultivo da cana-de-açúcar.

\section{CONCLUSÕES}

1. O aumento na temperatura e principalmente na $\left[\mathrm{CO}_{2}\right]$ para a cultura da cana-de-açúcar é benéfico com relação às relações hídricas solo-planta-atmosfera, reduzindo o efeito do principal fator de estresse para a cultura.

2. O aumento na temperatura e $\left[\mathrm{CO}_{2}\right]$ pode aumentar as taxas de fotossíntese.

3. As regiões marginais atualmente cultivadas serão beneficiadas tornando-se menos restritivas à cultura da canade-açúcar.

4. É provável que as mudanças climáticas resultem em alterações no sistema de manejo da cultura, uma vez que plantas daninhas, pragas e doenças, serão beneficiadas.

\section{Literatura Citada}

Ainsworth, E.A.; Long, S.P. What have we learned from 15 years of free air $\mathrm{CO}_{2}$ enrichment (FACE)? A meta-analytic review of the responses of photosynthesis, canopy properties and plant production to rising $\mathrm{CO}_{2}$. New Phytologist, n.165, p.351-372, 2005.

Alexandrov, V. A.; Hoogenboom, G. The impact of climate variability and change on crop yield in Bulgaria. Agricultural and Forest Meteorology, v.104, p.315-327, 2000.

Allen, L.H.; Jones, P.H.; Jones, J.W. Rising atmospheric CO2 and evapotranspiration. In: Advances in evapotranspiration. St. Joseph: ASAE, 1985.p.13-27.

Alves, L. M.; Marengo, J. Assessment of regional seasonal predictability using the PRECIS regional climate modeling system over South America. Theoretical and Applied Climatology, v.100, p.337-350, 2010.

Aranha, C.; Yahn, C. A. Botânica da cana-de-açúcar. In: Paranhos, S. B. (coord.) Cana-de-açúcar: Cultivo e utilização. Campinas: Fundação Cargill, 1987. Cap.1, p.3-13.

Assad, E. D.; Pinto, H. S.; Zullo Jr., J.; Evangelista, S. R. M.; Otavian, A. F.; Avila, A. M. H. de; Evangelista, B. A.; Marin, F. R.; Macedo Jr, C.; Pellegrino, G. Q.; Pereira-Coltri,P.; Coral, G. Aquecimento Global e a Nova Geografia da Produção Agrícola no Brasil. 2.ed. Campinas: EMBRAPA, 2008, v.1, 55p . 
Barros, G. S. A. C. Brazil: The challenges in becoming an agricultural superpower. In: Brainard, L.; Martinez-Diaz, L. (ed.). Brazil as an economic superpower? Understanding Brazil's changing role in the global economy. Washington: The Brookings Institution, 2009. Cap.4, p.81-109.

Bombardi, R. J.; Carvalho, L. M. V. de; Variabilidade do regime de monções sobre o Brasil: o clima presente e projeções para um cenário com $2 \mathrm{xCO}_{2}$ usando o modelo MIROC. Revista Brasileira de Meteorologia, v.23, p.58-72, 2008.

Bressan Filho, A. Os Fundamentos da crise do setor sucroalcooleiro no Brasil. In: Companhia Nacional de Abastecimento. Os fundamentos da crise do setor sucroalcooleiro no Brasil. Brasília: CNP, 2009. 86p.

Canabrava, A.P. História econômica: Estudos e pesquisas. São Paulo: UNESP. 2005. 320p.

Chakraborty, S.; Murray, G. M.; Magarey, P. A.;Yonow, T.; O’Brien, R. G.; Croft, B. J.; Barbetti, M. J.; Sivasithamparam, K; Old, K. M.; Dudzinski, M. J. Potential impact of climate changes on plant diseases of economic significance to Australia, Australasian Plant Pathology, v.27, p.15-35, 1998.

Coakley, S. M.; Scherm, H.; Chakraborty, S. Climate change and plant disease management. Annual Reviews of Phytopathology, v.37, p.399-426, 1999.

CONAB - Companhia Nacional de Abastecimento. Canade-açúcar: Safra 2011/2012 terceiro levantamento. Acompanhamento da safra brasileira. Brasília, 2011. 20p.

DaMatta, F. M.; Grandis, A.; Arenque, B. C.; Buckeridge, M. $\mathrm{S}$. Impacts of climate changes on cropp hysiology and food quality. Food Research International, v.43, p.1814-1823, 2010.

Drake, B. G.; Gonzàlez-Meler, M. A.; Long, S. P. More efficient plants: A consequence of rising atmospheric $\mathrm{CO}_{2}$ ? Annual Review of Plant Physiology and Plant Molecular Biology, v.48, p.607-637, 1997.

Farias, C. H. A. de; Fernandes, P. D.; Azevedo, H. M. de; Dantas Neto, J. Índices de crescimento da cana-de-açúcar irrigada e de sequeiro no estado da Paraíba. Revista Brasileira de Engenharia Agrícola e Ambiental, v.12, p.356-362, 2008.

Fuhrer, J. Agroecosystem responses to combinations of elevated $\mathrm{CO}_{2}$, ozone, and global climate change. Agriculture, Ecosystems and Environment, v.97, p.1-20, 2003.

Ghannoum, O.; Caemmerer, S. von; Ziska, L. H.; Conroy, J. $\mathrm{P}$. The growth response of $\mathrm{C} 4$ plants to rising atmospheric $\mathrm{CO} 2$ partial pressure: a reassessment, Plant, Cell and Environment, v.23, p.931-942, 2000.

Gouvêa, J. R. F.; Sentelhas, P. C.; Gazzola, S. T.; Santos, M. C. Climate changes and technological advances: Impacts on sugarcane productivity in tropical southern Brazil. Scientia Agricola, v.66, p.593-605, 2009.

Grantz, D. A.; Meinzer, F. C. Stomatal responses to humidity in a sugarcane field: Simultaneous porometric and micrometeorlogical measurements. Plant Cell and Environment, v.13, p.27-37, 1990.

James, G. Sugarcane. 2.ed. Oxford: Blackwell, 2004. 216p.

Kimball, B.; Bernacchi, C. J. Evapotranspiration, canopy temperature, and plant water relations. Managed Ecosystems and $\mathrm{CO}_{2}$, v.187, p.311-324, 2006.
Leakey, A. D. B.; Uribelarrea, M.; Ainsworth, E. A.; Naidu, S. L.; Rogers, A.; Ort, D. R.; Long, S. P. Photosynthesis, productivity, and yield of maize are not affected by open-air elevation of $\mathrm{CO}_{2}$ concentration in the absence of drought. Plant Physiology, v.140, p.779-790, 2006.

Leakey, A. D. B.; Xu, F.; Gillespie, K. M.; McGrath, J. M.; Ainsworth, E. A.; Ort, D. R. The genomic basis for stimulated respiratory carbon loss to the atmosphere by plants growing under elevated carbon dioxide. Proceedings of the National Academy of Sciences, v.106, p.3597-3602, 2009.

Manzatto, C. V. (org.). Zoneamento agroecológico da cana-deaçúcar. Rio de Janeiro: Embrapa Solos, 2009. 55p.

Marin, F. R.; Jones, J. W.; Singels, A.; Royce, F.; Assad, E. D.; Pellegrino, G. Q.; Barbosa, F. J. Climate change impacts on sugarcane attainable yield in Southern Brazil. Climatic Change, v.1, p.1-13, 2012.

Morgan, J. A.; LeCain, D. R.; Pendall, E.; Blumenthal, D. M.; Kimball, B. A.; Carrillo, Y.; Williams, D. G.; White, J. H.; Dijkstra, F. A.; West, M. C4 grasses prosper as carbon dioxide eliminates desiccation in warmed semi-arid grassland. Nature, v.476, p.202-205, 2011.

Nitsch, M. O programa de biocombustíveis Proálcool no contexto da estratégia energética brasileira. Revista de Economia Política, v.11, p.123-138, 1991.

Ottman, M. J.; Kimball, B. A.; Pinter, P. J.; Wall, G.W.; Vanderlip, R.L.; Leavit, S.W.; LaMorte, R.L.; Matthias, A.D.; Brooks, T.J. Elevated $\mathrm{CO}_{2}$ increases sorghum biomass under drought conditions. New Phytologist, v.150, p.261273, 2001.

Owensby, C. E.; Ham, J. M.; Knap, A. K.; Bremer, D.; Auen, L. M. Water vapor fluxes and their impact under elevated CO2 in a C4-tallgrass prairie. Global Change Biology, v.3, p.189-195, 1997.

Patterson, D. T.; Westbrock, J. K.; Joyce, R. J. V.; Lingren, P. D.; Rogasik, J. Weeds, insects and diseases, Climate Change, v.43, p.711-727, 1999.

Rogers, H. H.; Bingham, G. E.; Cure, J. D.; Smith, J. M.; Surano, K.A. Responses of selected plant species to elevated carbon dioxide in the field. Journal of Environmental Quality, v.12, p.569-574, 1983.

Sentelhas, P. C.; Pereira, A. R.; Marin, F. R.; Angelocci, L. R.; Alfonsi, R. R.; Caramori,P. H.; Swart, S. BHBrasil - Balanços hídricos climatológicos de 500 localidades brasileiras. http://www.leb.esalq.usp.br/nurma.html. 19 Nov. 2012.

Souza, A. P.; Gaspar, M.; Silva, E. A.; Ulian, E. C.; Waclawosky, A. J.; Nishiyama Jr., M. Y.; Santos, R. V.; Teixeira, M. M.; Souza, G. M.; Buckeridge, M. S. Elevated CO2 increases photosynthesis, biomass and productivity, and modifies gene expression in sugarcane. Plant, Cell \& Environment, v.31, p.1116-1127, 2008.

Thomson, L. J.; Macfadyen, S.; Hoffmann, A. A. Predicting the effects of climate change on natural enemies of agricultural pests. Biological Control, v.52, p.296-306, 2010.

Thornton, P. K.; Jones, P. G.; Alagarswamy, G.; Andresen, J. Spatial variation of crop yield response to climate change in East Africa. Global Environment Change, v.19, p.54-65, 2009. 
Tolbert, N. E., Zelitch, I. Carbon metabolism. In: Lemon, E. D. (ed.) $\mathrm{CO}_{2}$ and plants: The response of plants to rising levels of carbon dioxide. Carbon metabolism. In $\mathrm{CO}_{2}$ and plants: The response of plants to rising levels of carbon dioxide, ed. E. R. Lemon, Boulder: University of California, Westview press, 1983.p.21-64.

Trenberth, K. E.; Jones, P. D.; Ambenje, P.; Bojariu, R.; Easterling, D.; Tank, A. K.; Parker, D.; Rahimzadeh, F.; Renwick, J. A.; Rusticucci, M.; Soden, B.; Zhai, P. Observations: Surface and atmospheric climate change. In: Solomon, S.; Qin, D.; Manning, M.; Chen, Z.; Marquis, M.; Averyt, K. B.; Tignor, M.; Miller, H. L. (ed.). Climate change 2007: The physical science basis. Contribution of working group I to the fourth assessment report of the intergovernmental panel on climate change. Cambridge: Cambridge University Press, United Kingdom, 2007.Cap.3, p.235-336.

Venkataramana, S.; Gururaja Rao, P. N.; Naidu, K. M. The effects of water stress during the formative phase on stomatal resistance and leaf water potential and its relationship with yield in ten sugarcane varieties. Field Crops Research, v.13, p.345-353, 1986.
Vu, J. C. V; Allen Jr., L.H. Stem juice production of the C4 sugarcane (Saccharum officinarum) is enhanced by growth at double-ambient $\mathrm{CO}_{2}$ and high temperature. Journal of Plant Physiology, v.166, p.1141-1151, 2009.

Vu, J. C. V.; Allen Jr., L. H.; Gesch, R. W. Up-regulation of photosynthesis and sucrose metabolism enzymes in young expanding leaves of sugarcane under elevated growth $\mathrm{CO}_{2}$. Plant Science, v.171, p.123-131, 2006.

Ziska, L. H. Evaluation of yield loss in field sorghum from a $\mathrm{C} 3$ and $\mathrm{C} 4$ weed with increasing $\mathrm{CO}_{2}$. Weed Science, v.51, p.914-918, 2003.

Ziska, L. H.; Bunce, J. A. Influence of increasing carbon dioxide concentration on the photosynthetic and growth stimulation of selected C4 crops and weeds. Photosynthesis Research, v.54, p.199-208, 1997.

Ziska, L. H.; Bunce, J. A. Plant responses to rising atmospheric carbon dioxide. In: Morison, J. I. L.; Morecroft, M. D. (ed.). Plant growth and climate change. Oxford: Blackwell Publishing, 2006. p.17-47. 